\title{
The training simulator for the project activity «Master Project»
}

\author{
Valentin S. Nikolaenko ${ }^{1, a}$ \\ ${ }^{1}$ Tomsk Polytechnic University, 634050 Lenin Avenue, 30, Tomsk, Russia
}

\begin{abstract}
The article presents the results of the research which has been conducted both for the classic and modern education methods. It also provides an overview of results of the analysis of technologies employing active learning methods and considers the concept of a training simulator as an innovative learning method. The academic course of Management is given as an example of a course within which the simulator may be used. The intended pedagogical results of the use of the training simulator conform fully to Law No.273 of the Russian Federation «On education», the Federal State Education Standard, and the Basic Educational Programme.
\end{abstract}

\section{Introduction}

Due to the multiple political and economical crises, the modern business environment is facing an acute shortage of young specialists who are able to make estimates, give forecasts, and make right managerial decisions. The problem of the lack of qualified specialists arises, amongst other reasons, out of an education process aimed at providing students with basic theoretical knowledge only, without developing their practical skills. It means that it is necessary to revise the training of young specialists as we switch over to new education models [1], such as «Education 2.0» [2] and «Education $3.0 »[3]$.

In this regard, the purpose of the article is to analyse and develop educational tools based on IT which form and develop professional and general cultural competencies of the learning process participants.

In order to achieve the purpose stated by the author of the article, it is suggested to solve the following tasks:

1. To conduct the analysis of the main classic and modern learning methods;

2. To research the «active» learning technology;

3. To develop the concept of a training simulator which would allow participants of the learning process to form and develop their professional and general cultural competencies.

\section{Basic learning methods}

Practice is one of the oldest learning methods where a participant of the learning process masters new tools and develops required skills. It should be noted that this method was actively used in the Middle Ages in teaching apprentices. In the modern education system this method has been transformed into internship and advanced training courses.

Transmission of material. The main idea of this method is to transfer knowledge about an object or the reality from one person (Teacher) to another (Student). The method of «Transmission of material» was widely used in ancient Greek schools where the Teacher told Students about the way the world is. In 1638, the pedagogical method «Transmission of material» was significantly improved by John Amos Comenius to the class-and-lesson system.

In the modern education system, the transmission of material is conducted in various ways, for example, classic lectures, independent textbook studies, masterclasses, and distance learning. Despite its wide usage in the Russian education system, this learning method has significant drawbacks:

- predominance of theory;

- a poor alignment of theory and practice;

- a risk of lack of necessary knowledge when solving real practical tasks.

Case study. It is generally thought that this method was developed in the University of Harvard when teaching doctors. The main idea of this method is to collect typical situations from everyday practice which Students can analyse and make suggestions on possible development scenarios. Using this method, Students form a professional way of thinking and the ability to make decisions in a range of typical practical tasks.

Game. The method of learning through games was first applied in the USSR. The business game conducted by Maria Birshtey in 1932, «Redesign of production due to drastic changes in the production programme», was aimed at solving production problems. However, group

\footnotetext{
a Corresponding author: nikolaenkovs@tpu.ru
} 
exercises for taking managerial decisions did not become widespread in Soviet programmes for training managers.

Among the developers of business games, it is necessary to mention G.P. Shchedrovitsky, Richard Duke, and Jan Klabbers [4].

The modern education process most often uses role play which shows typical professional situations and/or behavioural models.

Imitation. The idea to imitate various situations was first implemented in the field of military training where various combat situations were modelled for pilots with the help of flight simulators. The first digital training simulators were developed by RAND Corporation in 1955 and Carnegie Mellon University in 1958.

Simulators are based on models which are developed according to norms and rules of real practical activity. For instance, using imitation, a learning process participant can quickly master professional procedures and tools and form an idea of the relevant professional activity as a whole structure.

In Russia, the imitation method is usually referred as «simulation», «simulator», or «imitation game». A simulator is a mechanic or computer-aided device which imitates controlling a process, a vehicle, a machine, or an apparatus.

There are the following types of simulators:

- an aviation simulator (a flight simulator) is a device used for the ground training of pilots;

- a mountain skiing simulator (a ski simulator) is a device which allows learning the technique of mountain skiing and snowboarding as well as improving and developing skills necessary for highquality skiing;

- an infantry combat simulator is a set of software and hardware used for combat training of foot soldiers which enables to imitate real battlefield situations and enemy actions as well as to estimate and test one's own abilities;

- a business simulator is a device imitating business processes which is aimed at training students, specialists, and other participants of the learning process;

- a sports simulator is a device imitating sporting contests;

- an educational simulator is a device used for mass training or students which provides the development of practical competencies.

Business simulation is a themed business game which imitates (models) business environment. Business simulators are usually divided into three groups:

- computer-aided business simulators;

- board games;

- business games.

Computer-aided business simulators are interactive games which model the activity of a particular organisation or the processes which may take place at the market. Participants of the learning process use these simulators to act as the head of an organisation, optimize basic business processes, and try to make the organisation successful. A special computer programme performs the analysis of the business decisions being made. Computer-aided simulations are an imitation of management processes and managerial decision making which is as close to the reality as possible. Participants of the learning process manage an organisation, choose strategic goals of its development, make step-by-step tactical decisions, and establish connections with customers and the staff, i.e. they solve the same management and production problems which managers and leaders of organisations face.

Table 1. Organisations developing training simulators

\begin{tabular}{|c|c|c|}
\hline № & Name of organisation & $\begin{array}{c}\text { City } \\
\text { Country } \\
\end{array}$ \\
\hline 1 & Cesim & $\begin{array}{l}\text { Helsinki } \\
\text { (Finland) }\end{array}$ \\
\hline 2 & STS & $\begin{array}{c}\text { Lausanne } \\
\text { (Switzerland) }\end{array}$ \\
\hline 3 & $\begin{array}{l}\text { RANEPA } \\
\text { The Russian Presidential Academy of } \\
\text { the National Economy and Public } \\
\text { Administration under the President of } \\
\text { the Russian Federation (management, } \\
\text { project management, marketing, and } \\
\text { logistics) }\end{array}$ & $\begin{array}{l}\text { Moscow } \\
\text { (Russia) }\end{array}$ \\
\hline 4 & TATA Interactive Systems & Germany \\
\hline 5 & $\begin{array}{l}\text { Simformer } \\
\text { Information platform for business } \\
\text { simulations }\end{array}$ & $\begin{array}{l}\text { Moscow } \\
\text { (Russia) }\end{array}$ \\
\hline
\end{tabular}

Educational simulators are one of the brightest innovations in education. Such devices owe their appearance to the development of information technologies which allow modelling various practical tasks in a short time span.

The simulation method combines the advantages of various learning methods. For instance, a learning simulation can be as varied as case studies, but, unlike case studies, simulators allow the participants not only to make managerial decisions but also see possible consequences. Similarly to projects, simulation allows communication between people: relationships in a team, responsibility for decisions, dealing with uncertainty, lack of time, resources, information, etc. Using learning simulation, participants of the learning process work out and train such important personal and professional competencies as:

- teamwork with the demonstration of leadership abilities;

- analysis and forecast of competitors' actions;

- forecast of changes in the outside circumstances;

- organisation of work activities;

- time management, etc.

An important difference between learning simulations and real projects is the right for a mistake (for example, a removal from office, the winding-up of a project, etc.). Simulation creates a risk-free environment 
where a participant of the learning process can analyze their mistakes and learn from them.

The simulation market in the world, including Russia, has been developing rapidly during the last fifteen years. The catalyst for the development of educational simulators (such as imitations, training simulators, and games) was the quick development of information technologies capable of performing complex modelling of various practical tasks. Also, the development of simulators was influenced by the growing demand for qualified staff: for employees with well-developed competencies and experience of solving practical tasks. It should be noted that learning simulations allow participants of the learning process not only to develop their personal and professional competencies promptly, but also to form new techniques and skills necessary for completing tasks.

However, despite the fast growth of the market of simulators, the world market amounts to, at most, 30 academic developers of training simulators. The main developers of simulators are academic staff members, and also, simulators are actively developed by training companies.

The main consumers of such simulators are higher educational institutions, corporations in need of professional training courses, and business schools. Besides, simulators are used for practical learning in such an organisation as the American Institute of Banking.

Thus, we can consider the following characteristics to be the positive qualities of learning simulations:

- realism (a participant of the learning process makes managerial decisions in real time, close to real-life circumstances);

- replay (the same situation can be played under several scenarios, which allows mastering the necessary material better);

- feedback (contact with a participant of the learning process is maintained);

- motivation (simulation can be very entertaining and engaging);

- testing of participants of the learning process (a simulator runs tests on studied materials automatically).

Project. Project is considered to be one of the most effective learning methods [5]. The main idea of the project method is to engage a participant of the learning process into the system of collective work which is aimed at solving a practical task. Being engaged in project-planning, analysis, and other activities, a participant of the learning process masters the principles of completing various types of tasks. Group work makes participants think about ways to organise joint work, establish communication, etc. It should be noted that project-based learning systems are most effective when mastering management principles [6].

Using the results of the carried out research of learning methods which involve information technologies (IT), it is possible to describe the elements and methods of learning which have to include «technical educational innovations». Such educational innovations are expected to:

- provide participants of the learning process with upto-date subject content;

- use «active» learning methods;

- be based on the modern infrastructure.

It should be noted that «innovative educational technologies» are often understood only as a more active use of information technologies (the Internet, video conferences, multimedia, etc.). The present article interprets «innovative educational technologies» as the use of new learning methods which includes the following:

- up-to-date content which develops professional competencies conforming to nowadays practical tasks;

- educational information compiled in the form of multimedia learning materials which can be easily sent via modern communication means;

- IT-based infrastructure.

\section{Technologies of «active» learning}

Learning methods should be «active», i.e. the priority should be given to the interaction between the teacher and students with their engagement in the learning process.

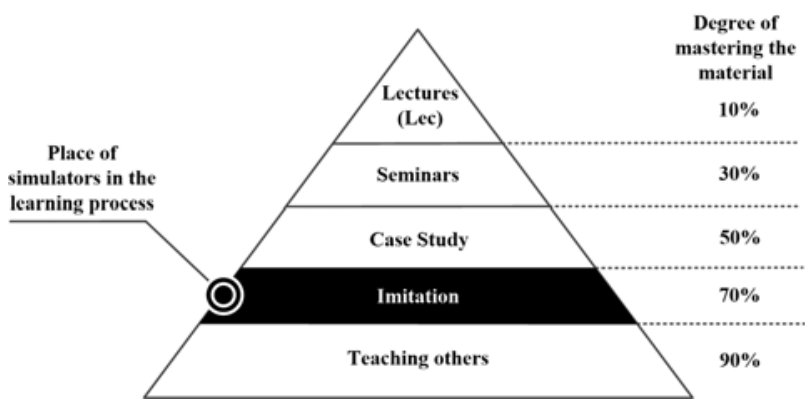

Fig. 1. The learning pyramid. Cone of experience by Edgar Dale

This criterion of «technological innovations» may be applied to the Case Study method as it deals with the elaboration of a particular practical situation, the Business Simulations method, and the Project Based method.

The analysis conducted by the author of this article has shown that Russia needs cases for study designed for different companies and industries. Another result of the conducted analysis is the discovery of the fact that higher educational institutions rarely practice projectbased learning in the framework of which a group of students could implement a project for an organisation, maintaining communication with specialists and managers of the given organisation. As for the use of training simulators, they are extremely rare.

In a range of foreign schools simulators are used as learning courses integrating several disciplines. For instance, at Rotman School at the University of Western Ontario (Toronto, Canada), the China-European 
International Business School (Shanghai, China), and at Tepper Business School at Carnegie Mellon University (Pittsburgh, USA) courses with simulators last from 1 week up to 3 months.

It is necessary to note that, at the Russian Presidential Academy of the National Economy and Public Administration under the President of the Russian Federation, a department has been created - the Centre of Innovative Educational Technologies - which specializes in research and project development in the field of educational technologies. This centre has developed more than 10 business simulations for various fields, case studies for the banking industry, and a range of corporate programmes for training management personnel.

\section{Simulator of project activity «Master Project»}

«Master Project» is a simulator aimed at creating an educational environment. It is used for the imitation of processes typical of project activity. This simulator is meant for contributing to the pedagogical process in such disciplines as:

- management;

- manufacturing process management;

- company economics;

- marketing;

- strategic management;

- financial management;

- forecasting and planning of company finance;

- company planning;

- anti-crisis management;

- theory of making managerial decisions, and other management-related disciplines.

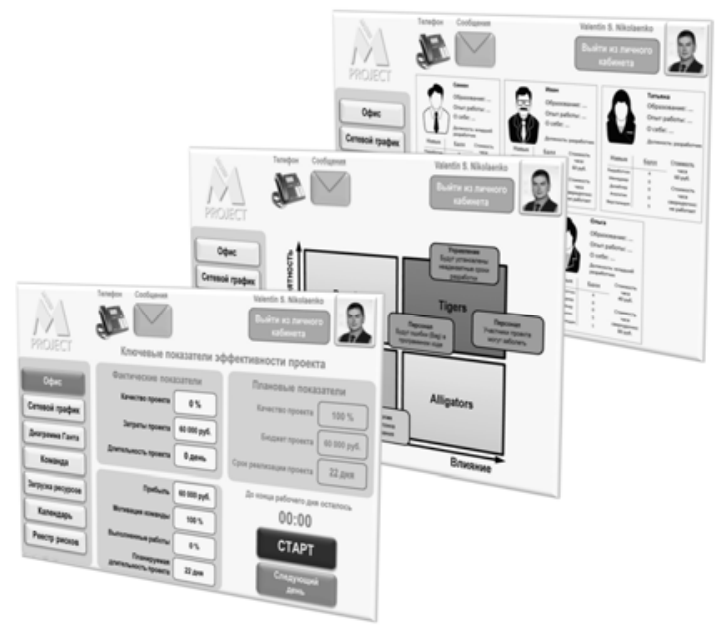

Fig. 2. An example of the functional interface of the training simulator «Master Project»

The simulator of the project activity «Master Project» can be integrated in the learning process of various disciplines, and it can replace practical classes (Pr), laboratory works (Lab), and writing course works $(\mathrm{Cw})$.

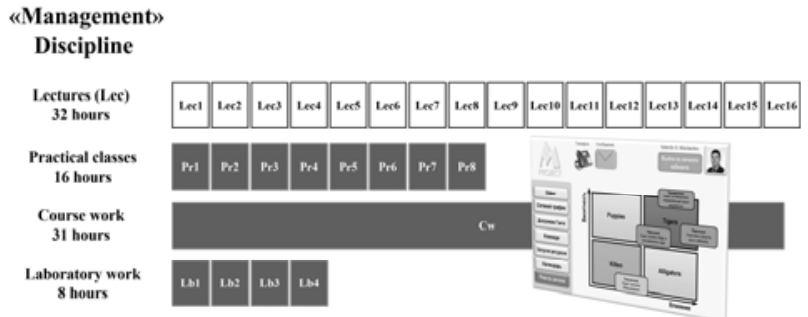

Fig. 3. An example of the usage of the training simulator «Master Project»

Let us look at a particular case of using the simulator of project activity «Master Project» in the framework of a course of «Management» (Figure 3 ). This course has been developed in accordance with Law No.273 of the Russian Federation «On education» and the Federal state education standard. The results of learning correlate with the Basic Educational Programme.

The pedagogical result of the use of the training simulator «Master Project» is a research engineer with well-developed competencies in the the areas of managerial decision making, management, marketing, and business.

\section{Conclusion}

Based on the conducted research, it has been established that the educational process in the higher educational establishments of the Russian Federation needs innovative educational technologies forming and developing professional and general cultural competencies. For the purposes of solving this problem, this work aimed to analyse learning technologies that enable active development of not only knowledge but also skills and abilities of participants of a learning process.

\section{References}

1. E. Dale, Audiovisual methods in teaching. 3rd edition (New York: The Dryden Press; Holt, Rinehart and Winston, 1969)

2. O.N. Petukhov, V.S. Nikolaenko, International Multidisciplinary Scientific Conferences on Social Sciences and Arts, 3, 579-586 (2014)

3. I.V. Krakovetskay, T.R. Rakhimov, V.S. Nikolaenko, The Concept of Virtual Education Enviroment Based on the Principles of Education 2.0, Web 2.0 and Project Activities. The Triple Helix XII International Conference "Triple Helix and Innovation-Based Economic Growth: New Frontiers and Solutions» (2014)

4. R. Duke, J. Geurts, Policy Games for Strategic Management; Pathways into the Unknown. The Magic Circle: Principles of Gaming \& Simulation (Rotterdam: Sense Publishers, 2006)

5. Project management body of knowledge. Guide 4th edition (PMBOK-4). Project Management Institute (PMI), 506 (2008)

6. P. Sanghera, PMP exam in depth, second edition: project management professional study guie for the 
PMP exam. Course technology, a part of Cengage

Learning (2010) 